Cipango $\begin{aligned} & \text { Cipango } \\ & \text { Cahiers d'études japonaises }\end{aligned}$

18 | 2011

Le Japon et le fait colonial I

\title{
La figure du heitai-sakka dans la «Trilogie du soldat » de Hino Ashihei
}

\section{Guillaume Muller}

\section{(2) OpenEdition}

1 Journals

\section{Édition électronique}

URL : https://journals.openedition.org/cipango/1628

DOI : $10.4000 /$ cipango. 1628

ISSN : 2260-7706

Éditeur

INALCO

\section{Édition imprimée}

Date de publication : 1 juin 2011

Pagination : 300-303

ISBN : 978-2-85831-195-8

ISSN : $1164-5857$

\section{Référence électronique}

Guillaume Muller, «La figure du heitai-sakka dans la «Trilogie du soldat » de Hino Ashihei », Cipango [En ligne], 18 | 2011, mis en ligne le 25 septembre 2013, consulté le 30 juin 2021. URL : http://

journals.openedition.org/cipango/1628; DOI : https://doi.org/10.4000/cipango.1628

Ce document a été généré automatiquement le 30 juin 2021.

\section{(c) (1) \&}

Cipango est mis à disposition selon les termes de la Licence Creative Commons Attribution - Pas d'Utilisation Commerciale 4.0 International. 


\title{
La figure du heitai-sakka dans la «Trilogie du soldat » de Hino Ashihei
}

\author{
Guillaume Muller
}

\section{RÉFÉRENCE}

Guillaume MULLER, La figure du heitai-sakka dans la « Trilogie du soldat » de Hino Ashihei, mémoire de Master 2, sous la direction d'Anne Bayard-Sakai, INALCO, 2012

1 Ce mémoire montre de quelle façon Hino Ashihei, lauréat du prix Akutagawa en 1937 alors qu'il était fantassin en Mandchourie, a mis en scène dans ses plus célèbres récits de guerre l'ambivalence de son identité de soldat-écrivain. L'étude porte sur la "Trilogie du soldat », constituée de Mugi to heitai (1938, un journal de campagne), Tsuchi to heitai (1938, un récit de premier débarquement) et Hana to heitai (1939, un récit de garnison en station); elle se fonde sur l'hypothèse que cette identité, largement acceptée et commentée en tant que fait historique par la critique, a une manifestation textuelle analysable en tant que telle dans la mesure où elle régit les modalités du récit.

2 L'aspect historique de la question fait l'objet de la première partie de ce travail : on y aborde le sens qu'a eu dans le discours de propagande l'existence d'auteurs et d'artistes ayant une expérience du front à la lumière de la notion de "fonction-auteur », ainsi que la manière dont Hino a investi celle-ci à la lisière du texte ; les premières éditions de la trilogie ont participé à entretenir la confusion entre texte et réalité au moyen d'un paratexte constitué notamment de photographies qui renforçaient la crédibilité de la parole de Hino. L'histoire de la réception du texte permet d'autre part de mesurer le succès de cette "fonction-auteur » depuis la critique de l'époque jusqu'à celle de l'« après après-guerre ».

3 En raison de l'hétérogénéité des textes, Mugi to heitai (qui prend la forme d'un journal) et Tsuchi to heitai (qui alterne lettres à un «petit frère » et entrées de journal) sont 
analysés séparément de Hana to heitai ; ces deux textes jouent d'une part sur une rhétorique du récit personnel, mettant en scène une écriture monotone adressée à soi ou à un proche, censée par là même garantir l'authenticité du récit, et d'autre part sur une défiance à l'égard de la littérature (ou plutôt à l'égard du cliché d'une littérature héroïque et romancée que Hino construit pour ainsi dire en creux). Ce rapport à la littérature est cependant plus complexe qu'il n'y paraît : les passages où Hino se décrit en train d'écrire, par exemple, sont le lieu d'un jeu de représentation de soi à l'occasion duquel Hino construit son image d'écrivain et dévoile ses hésitations face à une question proprement littéraire (à laquelle l'existence même du texte serait censée donner une réponse claire) : quel langage utiliser pour écrire la guerre ? Le paradoxe ne s'arrête cependant pas là : dans le cadre d'une écriture immédiate telle que celle mise en scène par Hino, les genres du journal et de la correspondance délèguent l'esthétique des descriptions et la construction de l'intrigue à la qualité du réel décrit, mais cet apparent abandon de l'auctorialité ne peut-il pas être également lu comme une réintégration déguisée des caractéristiques littéraires qu'il avait a priori exclues?

Le second problème que pose le surinvestissement de l'écriture personnelle dans Mugi to heitai et Tsuchi to heitai a trait à la notion même de littérature de guerre : ces récits d'une guerre vécue personnellement se posent également comme ceux de la guerre de tous les soldats qui n'ont pas la parole. Les notions de polyphonie et de porte-parole permettent de montrer comment le texte, quand il rapporte les expériences que d'autres soldats racontent à Hino, définit sa propre valeur; il se dessine là comme un intertexte de récits qui n'ont jamais existé, au sein duquel l'auteur inscrit son propre récit. En un mot, ce récit de soldat qui revendique sa banalité contient en soi la possibilité de son universalisation.

Hana to heitai est quant à lui étudié en tant qu'il contraste avec les textes précédents : récit d'un séjour en garnison, c'est-à-dire d'une guerre qui n'est plus une guerre, le dernier livre de la trilogie décrit des soldats mis en situation d'être autre chose que des soldats. Hino, qui est lui aussi concerné par ce phénomène, trouve l'occasion d'exister au moins partiellement en tant qu'écrivain parmi les soldats, et d'interagir avec une palette de personnages qui sont eux-mêmes scindés: un caporal peintre, un soldat amoureux d'une Chinoise, un libraire chinois qui veut détruire la Chine... Cet aspect inédit de la guerre s'accompagne d'une fictionnalisation presque ostentatoire qui contraste radicalement avec les textes précédents, et c'est la lecture de l'ensemble de la trilogie que cette hétérogénéité pousse à réinterroger - le soldat-écrivain en tant qu'instance narrative peut être réduit à la coïncidence de ces deux identités dans la vie historique de l'auteur. 